\title{
Variation in physician reimbursement for endoscopy across Canada
}

\author{
Lee S Roth MD, Paul C Adams MD FRCPC
}

\author{
LS Roth, PC Adams. Variation in physician reimbursement \\ for endoscopy across Canada. Can J Gastroenterol \\ 2009;23(7):503-505.
}

BACKGROUND: Endoscopy accounts for a significant proportion of income for physicians practicing gastroenterology. Fees are set provincially, and the consistency with regard to compensation for colonoscopy and gastroscopy across the provinces has yet to be established. OBJECTIVE: To compare and contrast provincial endoscopy fees across Canada and internationally.

METHODS: Provincial and territorial ministries responsible for health care were contacted for their most current fee schedule. This was reviewed, and the billing amounts for colonoscopy and endoscopy collected. International contacts were made with regard to rates outside of Canada.

RESULTS: The mean ( \pm SD) national fee for gastroscopy was $\$ 114.19 \pm \$ 31.47$ per procedure, with a range of $\$ 52.50$ to $\$ 156.10$. Physician billing nationally averaged $\$ 170.99 \pm \$ 33.49$ per colonoscopy procedure, with a range of $\$ 105.00$ to $\$ 223.00$. The province of Quebec provided the least amount of compensation for both procedures, and the province of Nova Scotia provided the most for both procedures.

CONCLUSION: Physician fees for gastroscopy and colonoscopy vary widely among the provinces, and, on average, seem to be less than international rates.

\section{Variation du montant versé au médecin pour une endoscopie au Canada}

HISTORIQUE : L'endoscopie représente une portion significative du revenu des gastro-entérologues. Chaque province a son barème tarifaire et aucune concordance n'a encore été établie en ce qui a trait au paiement proposé pour la coloscopie et la gastroscopie entre les différentes provinces.

OBJECTIF : Comparer et mettre en relief les différences de tarifs pour l'endoscopie au Canada et ailleurs dans le monde.

MÉTHODE : Les auteurs se sont informés des barèmes tarifaires les plus récents auprès des responsables des soins de santé des provinces et des territoires. Cette information a été mise en parallèle avec les demandes de facturation pour coloscopie et gastroscopie. Les auteurs ont établi des contacts avec les autorités d'autres pays pour se renseigner sur les taux ailleurs dans le monde.

RÉSULTATS : Le coût national moyen ( \pm É.-T.) pour la gastroscopie a été établi à 114,19\$ \$31,47\$ par intervention. L'éventail allait de 52,50 \$ à 156,10 \$. À l'échelle nationale, les médecins facturaient en moyenne $170,99 \$ \pm 33,49 \$$ par coloscopie, l'éventail allant de $105 \$ 223$ à C'est la province de Québec qui offrait le moins pour les deux interventions et la province de la Nouvelle-Écosse qui offrait le plus.

CONCLUSION : Les frais médicaux pour gastroscopie et coloscopie varient énormément d'une province à l'autre et en moyenne, semblent inférieurs aux taux établis ailleurs dans le monde.

Key Words: Canada; Colonoscopy; Endoscopy; Reimbursement

$\mathrm{F}$ rom its inception in 1806 by Bozzini, endoscopy has had the potential to provide vital information regarding the lumen of many bodily cavities. The technology has come a long way from Bozzini's 'lichtleiter' (1), and currently is used by a number of specialties, particulary those involved in the diagnosis and treatment of alimentary disorders.

In gastroenterology, endoscopy comprises an important component of the physician's diagnostic and therapeutic armamentarium. Accordingly, gastroenterologists and other physicians garner much of their income from endoscopic procedures such as gastroscopy and colonoscopy. Physician billing for these procedures across Canada is set by the provincial ministries responsible for health care in consultation with the provincial medical associations. There is no nationwide standardization of these fees, and indeed, a comparison of endoscopy fees across the provinces would be of interest to many clinicians. Disseminating this data not only would allow clinicians to compare billing information, but may help spur growth and development in practice efficiency, which would provide improved access to care for all Canadians. In this era of increasingly strong calls for a colon cancer screening approach using colonoscopy, understanding the basis and mechanism for determining remuneration for endoscopy billing is imperative to provide the resources to implement such a program.

The present study aimed to compare provincial physician fees for both upper and lower endoscopy and to contrast them with international rates.

\section{METHODS}

The study was intended to be an observational examination of current physician fees for endoscopy across the country. The design was simply to collect and report information regarding procedural fees along with comparable international values.

Provincial ministries responsible for health care were contacted for their physician fee schedule. Most ministries had their schedule available on-line, and for those that did not or if further information was required to ascertain the exact amount, telephone or e-mail inquiries were made. Rates for

Division of Gastroenterology, Department of Medicine, University of Western Ontario, London Health Sciences Centre, London, Ontario

Correspondence: Dr Lee Roth, Division of Gastroenterology, Department of Medicine, London Health Sciences Centre, 339 Windermere Road,

Room ALL-330, London, Ontario N6A 5A5. Telephone 519-685-8500, fax 519-663-3549, e-mail lroth@uwo.ca

Received for publication October 20, 2008. Accepted December 7, 2008 


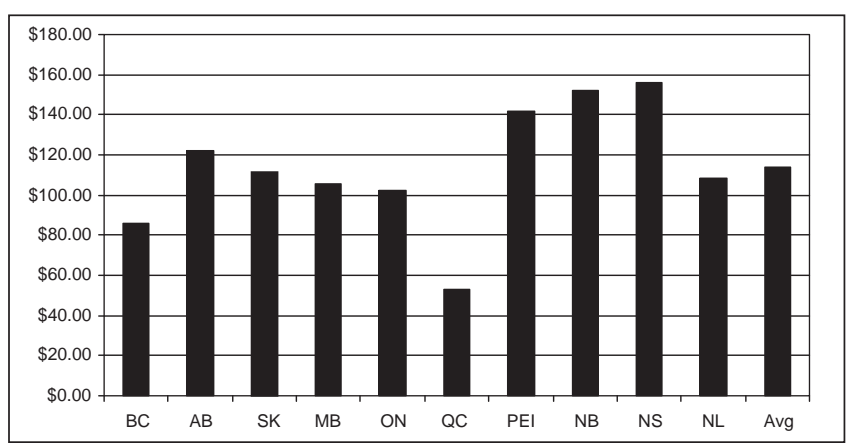

Figure 1) Provincial and average national rates for gastroscopy. Avg Average of provincial rates; AB Alberta; BC British Columbia; MB Manitoba; NB New Brunswick; NL Newfoundland and Labrador; NS Nova Scotia; ON Ontario; PEI Prince Edward Island; QC Quebec; SK Saskatchewan

esophagogastroduodenoscopy without biopsy or intervention, and colonoscopy to the cecum (when rate available) without biopsy or intervention were collected. Data from the two Canadian territories that provide these services on a fee-forservice basis were collected and reported in a separate category.

International rates were collected using information gathered from personal contact with endoscopists in countries such as Australia, Brazil, France and Italy. In the United States Medicare system, fees vary depending on which geographical area the procedure is performed, even within a given state. A few samples were taken from border states such as Michigan, New York and Washington. Currency values were converted using exchange rates that were current at October 20, 2008.

\section{RESULTS}

Data from all 10 provinces and two of the territories were collected. International rates were collected from Australia, France, Italy and from the Medicare system for three American States: Michigan, New York and Washington.

Nine of the 10 provinces had their fee schedule posted online, with Nova Scotia being the only province requiring further inquiry. The Northwest and Yukon Territories had their schedule posted on-line. Nunavut was contacted and reported that these procedures are not performed in their jurisdiction on a fee-for-service basis.

The national mean $( \pm$ SD) fee for gastroscopy was $\$ 114.19 \pm \$ 31.4$ per procedure, with a median value of $\$ 110.50$. The fee ranged from $\$ 52.50$ in Quebec to $\$ 156.10$ in Nova Scotia. The remaining provincial values are presented in Figure 1 with the national average. Data from the territories reported values of $\$ 178.70$ and $\$ 213.33$ for the Yukon and Northwest Territories, respectively.

Colonoscopy fees ranged from $\$ 105.00$ in Quebec to $\$ 223.00$ in Nova Scotia, with a mean national fee of $\$ 170.99 \pm \$ 33.49$, and a median value of $\$ 170.86$ per procedure. The remaining provincial values for colonoscopy are presented in Figure 2 with the national average. Colonoscopy fee data from the territories reported values of $\$ 398.10$ and $\$ 201.43$ for the Yukon and Northwest Territories, respectively.

International data showed that in Australia, fees were AUS $\$ 159.95$ (CAD \$143.41) for gastroscopy and AUS \$301.90 (CAD \$270.68) for colonoscopy, with rates for private care

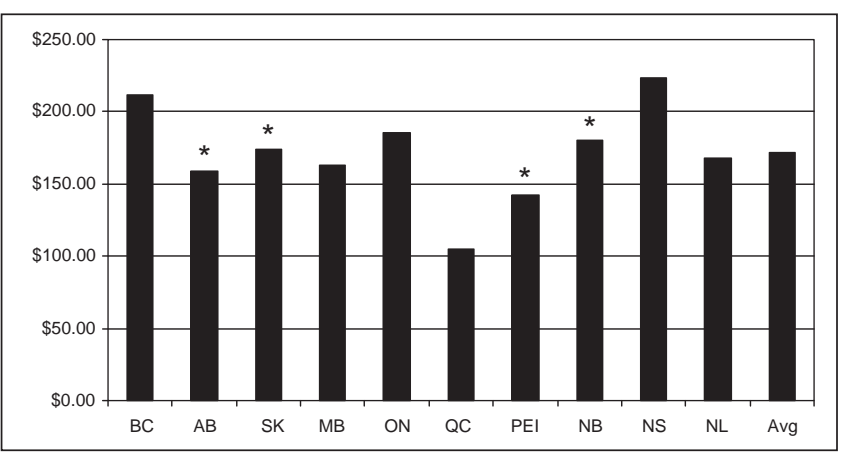

Figure 2) Provincial and average national rates for colonoscopy. Avg Average of provincial rates; $A B$ Alberta; $B C$ British Columbia; MB Manitoba; NB New Brunswick; NL Newfoundland and Labrador; NS Nova Scotia; ON Ontario; PEI Prince Edward Island; QC Quebec; SK Saskatchewan. *Fees that include routine biopsy

varying. French physicians are paid €96.00 (CAD \$152.93) per procedure for gastroscopy and $€ 156.60$ (CAD \$249.49) for colonoscopy. In Italy, physicians bill the national healthcare service $€ 188.00$ (CAD \$288.91) for gastroscopy and €241.00 (CAD \$370.25) per procedure for colonoscopy. Medicare values in the United States were US \$130.73 (CAD \$155.04) and US $\$ 196.43$ (CAD \$232.97) in Michigan, US \$125.22 (CAD $\$ 148.54$ ) and US \$187.75 (CAD \$222.74) in New York State, and US \$129.26 (CAD \$153.35) and US \$193.66 (CAD $\$ 229.71$ ) in Washington for gastroscopy and colonoscopy, respectively. These rates are compared with the Canadian averages for gastroscopy and colonoscopy in Figures 3 and 4, respectively.

\section{DISCUSSION}

The results show a significant variation in physician fees for endoscopy across the country. The data consistently demonstrate that physicians in Nova Scotia are remunerated more for their services than in the rest of the country. Additionally, physicians in Quebec are consistently remunerated less than their colleagues across the country. A number of factors can account for this including local conditions and culture, physician demand and government policies.

Provincial fee schedules are set through a process that involves both the government and the provincial medical association. There are a number of committees that participate in setting fees for new procedures and updating fees for existing procedures. In Ontario, these are comprised of the Physician Service Committee and the Central Tariff Committee. When deciding on the assigned value, factors such as length of the procedure, expertise required, risk involved and complexity of the procedure play large roles. These fees are then passed along to the provincial ministry and negotiations concerning the final value are conducted, which also have to account for variables such as overhead costs and physician recruitment, and may account for some of the regional variations apparent in the present study.

Historical values usually set the starting point for fee negotiation, with this number coming from previous bargaining sessions. There was a previous movement to adjust amounts based on the quantity of resources and time that is involved with certain procedures. In Ontario, this approach was extensively deliberated but ultimately not implemented. The 


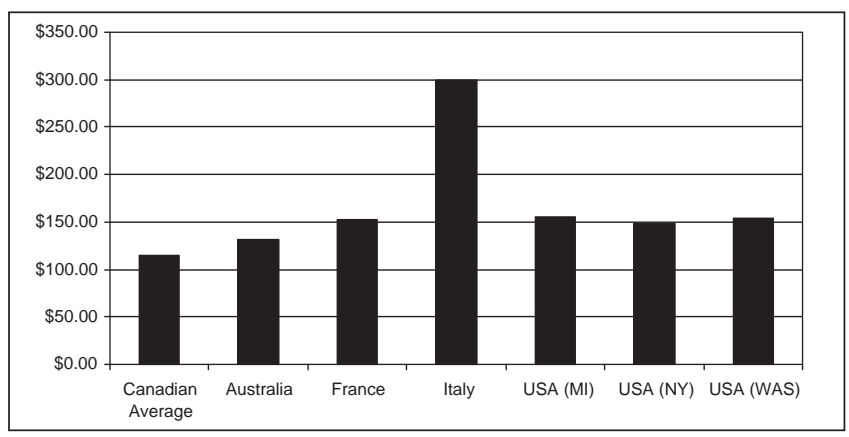

Figure 3) Average national fees for gastroscopy with international comparisons (all values converted to Canadian dollars; USA fees from Medicare). MI Michigan; NY New York; WAS Washington

American Medicare system has implemented a resource-based relative value scale from which physician fees are determined. The value is set by adjusting for procedure costs as well as other factors such as malpractice insurance, geographical considerations and physician time/workload, and converting this to a dollar amount. This system, however, has not met expectations because of controversies surrounding its administration (2).

Due to the fact that the data collected in the present study is numerical rather than descriptive in nature, there are limitations to the conclusions that may be drawn and confounding factors that may play a role. The timing of the fee schedules may be a factor, such that a province that has recently renegotiated its fee schedule may have higher fees than a province that has not adjusted its schedule. Given the gradual manner in which change is usually made to the fee schedule, this factor likely plays, at most, a minor role in the variation.

A major concern is that the present study does not compare intervention or biopsy fees. Although every effort was made to compare similar values, it is possible that certain extra manoeuvres may be included in the fee to account for the differences. For instance, one province may include the fee for any biopsies taken during a procedure, while another may allow the physician to bill extra for this procedure and therefore even out any disparities with the data collected. Indeed, when the schedules were reviewed, certain provinces such as New Brunswick and Saskatchewan had included routine biopsies in their colonoscopy fee, while other provinces such as Nova Scotia provided extra billing for cases in which biopsies are taken.

In addition to biopsy fees, certain provinces offer incremental fee increases depending on the extent of colon visualized with the colonoscope; therefore, the billing from one colonoscopy to another may vary. For example, in Ontario, one would bill $\$ 57.70$ for a colonoscopy that reached the descending colon, an additional $\$ 57.70$ to the splenic flexure, $\$ 34.90$ more for reaching the hepatic flexure and another $\$ 34.90$ for reaching the cecum. There is also a fee of $\$ 33.90$ for intubating the terminal ileum; however, this was not included in the calculated

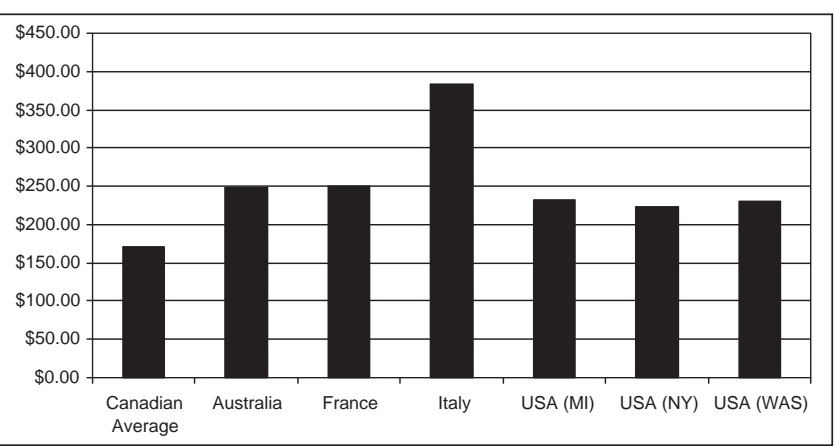

Figure 4) Average national fees for colonoscopy with international comparisons (all values converted to Canadian dollars; USA fees from Medicare). MI Michigan; NY New York; WAS Washington

value. Another example would be Quebec, which offers a similar approach to their colonoscopy billing with the fee for reaching the descending colon at $\$ 57.80$, increasing to $\$ 89.30$ if the transverse colon is reached and a final value of $\$ 105.00$ for anything past the ascending colon. Other provinces, such as British Columbia and Manitoba, offer a base amount for a colonoscopy, often requiring passage further than the splenic flexure. In the present study, every effort was made to standardize the payment from each province to the amount a physician performing a diagnostic esophagogastroduodenoscopy and a colonoscopy to the cecum without biopsies or polypectomy would be remunerated.

The international comparisons face similar concerns, along with a few unique issues. These values were collected from endoscopists in those countries, and just as Canada has variation between jurisdictions, so likely do these countries. Furthermore, these fees may include additional services, such as physician consultation or postprocedure care, that are not included in Canada's provincial fees. These values, however, are actual billing data from their respective countries and can serve as a broad comparison for local numbers, which is the desired purpose.

The present study demonstrates the considerable variation among provincial fee schedules for endoscopy. Additionally, averaged Canadian endoscopy fees are comparable, albeit consistently lower, than the values in other First World nations.

ACKNOWLEDGEMENTS: The authors acknowledge the assistance of Yves Deugnier, Patrick Gerstenberger, Daniel Grushka, Gary Jeffrey, Bruce Leibowitz and Antonello Pietrangelo in obtaining international data.

\section{REFERENCES}

1. Bush RB, Leonhardt H, Bush IV, Landes RR. Dr. Bozzini's Lichtleiter. A translation of his original article (1806). Urology 1974:3:119-23.

2. Ginsburg PB, Berensen RA. Revising Medicare's physician fee schedule - much activity, little change. N Eng J Med 2007;356:1201-3. 


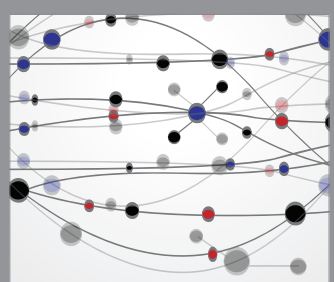

The Scientific World Journal
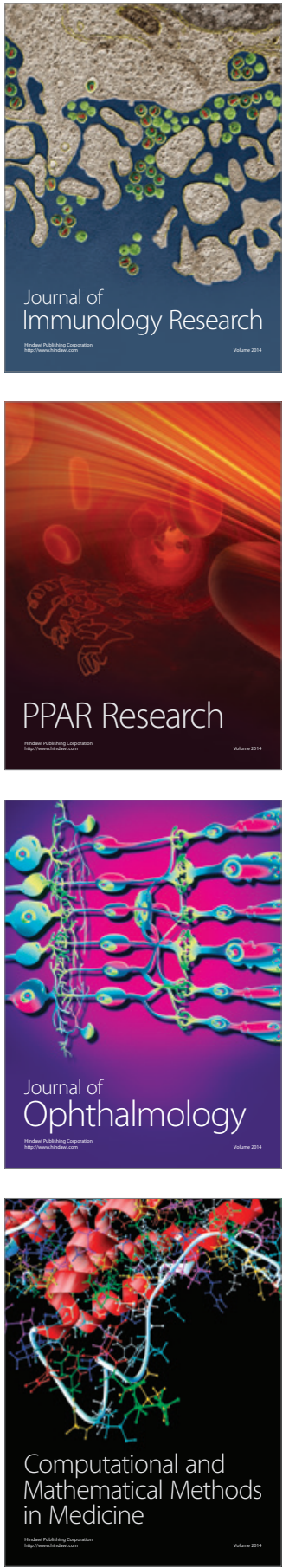

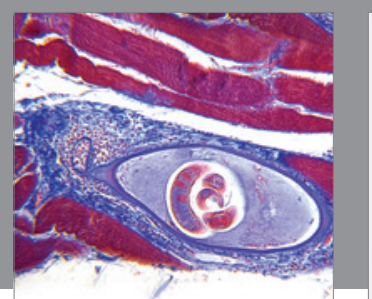

Gastroenterology Research and Practice

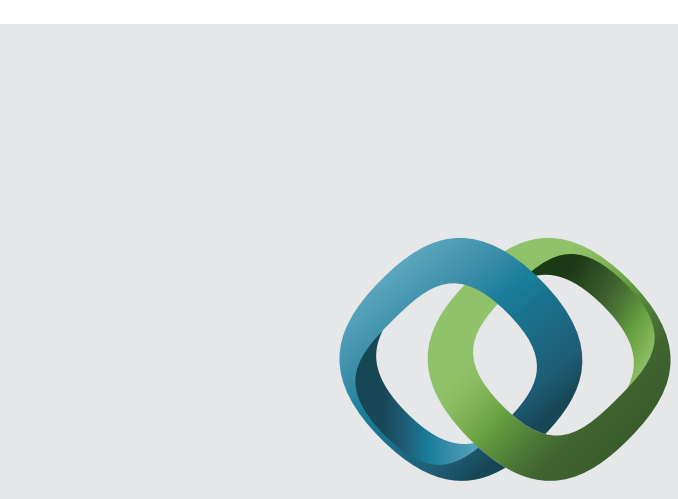

\section{Hindawi}

Submit your manuscripts at

http://www.hindawi.com
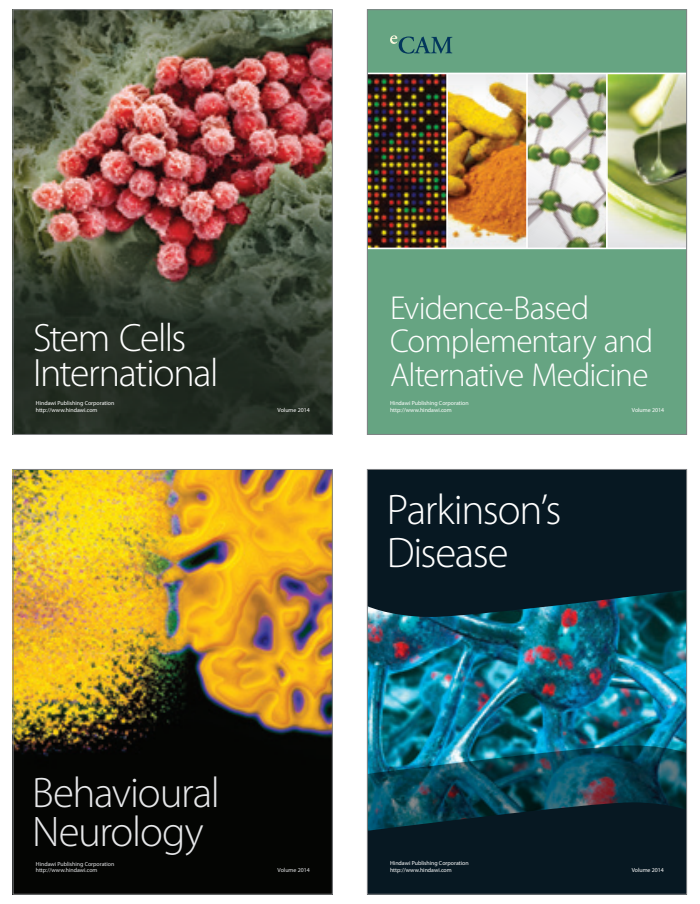
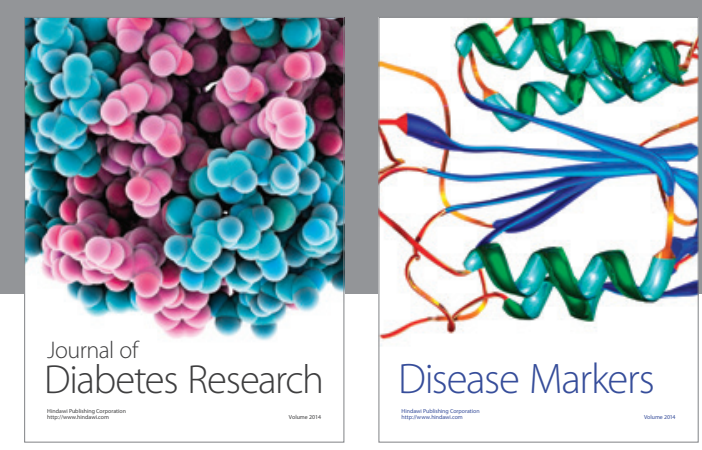

Disease Markers
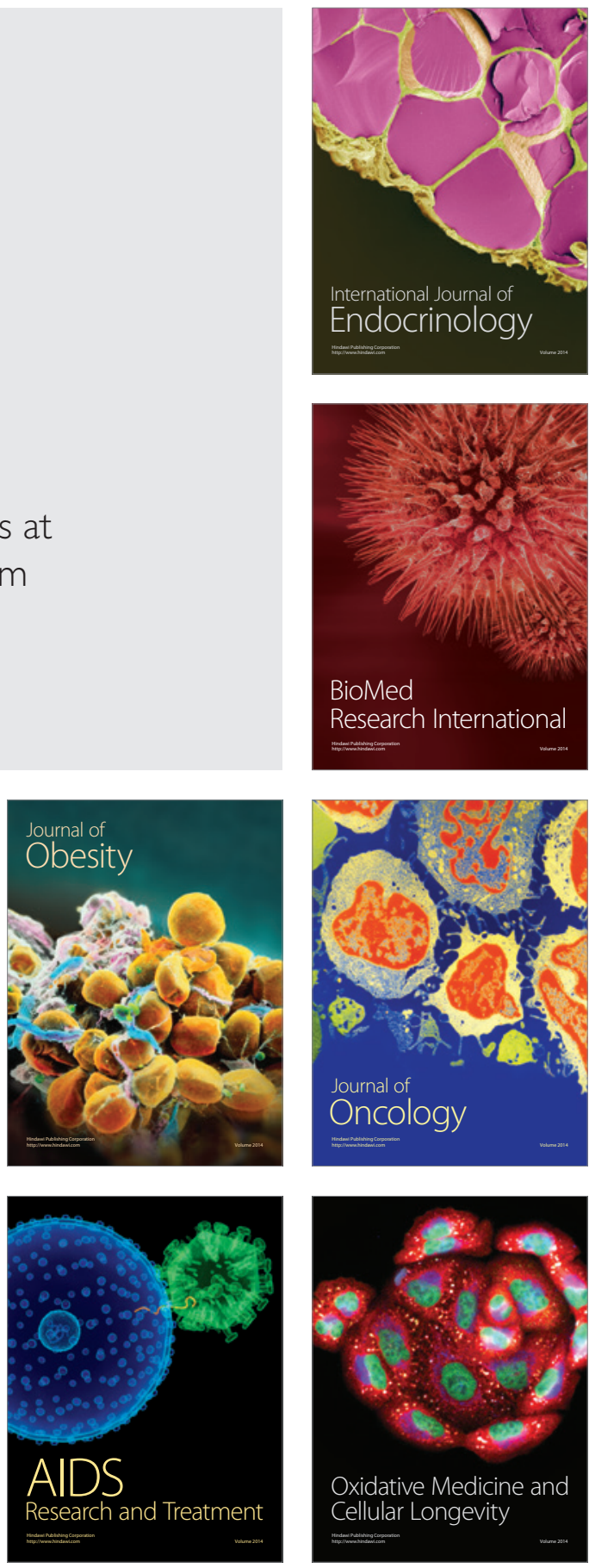